\title{
Van Allen remembered as belts turn 50
}

\author{
James Van Allen: The First Eight \\ Billion Miles \\ by Abigail Foerstner \\ University of lowa Press: 2007. 322 pp. \\ $\$ 37.50$
}

\section{William E. Burrows}

An iconic photograph marking the start of the space age shows three men thrusting a satellite above their heads. William Pickering, James Van Allen and Wernher von Braun lofted a scale model of the Explorer 1 satellite at the US National Academy of Sciences barely two hours after the real thing went into orbit on the night of 31 January 1958. It was the US response to the Soviet Union's provocative Sputnik launch months earlier.

Pickering headed the California Institute of Technology's Jet Propulsion Laboratory, which developed Explorer 1. Von Braun, a former Third Reich rocket prodigy who masterminded the V-2 missile, built the Jupiter-C launch rocket. Both engineers reacted to their feat with broad grins and irrepressible jubilation. The physicist Van Allen responded differently. His excitement was to come. Aboard Explorer 1 he had fixed a Geiger counter. It detected staccato cosmic-ray hits, which established that an enormous belt of radiation rings the Earth.

Van Allen "had a reputation as a practical physicist who applied the lessons of small-town Iowa ingenuity to outer space", writes biographer Abigail Foerstner. Her comprehensive and engaging portrait of Van Allen describes a tenacious individual whose modesty bordered on self-deprecation. For instance, he dubbed the phenomenal Explorer 1 mission "a 'shakedown' operation that succeeded on 'fool's luck".

Others lauded Van Allen's scientific achievement. "The Russians sent up the first satellite but America made the first scientific discovery there, the most momentous discovery of the International Geophysical Year," according to Walter Sullivan, then the preeminent science writer of The New York Times. At a conference in Europe soon after, the physicist Robert Jastrow used the term Van Allen radiation belt for the first time and the name soon stuck. A permanent new landmark in the heavens, and a hazardous region to be traversed by future spacecraft, the Van Allen belts comprise giant lobes of charged particles trapped by Earth's magnetic field that extend thousands of kilometres into space.

Foerstner, a former science writer for the Chicago Tribune, trains a journalist's eye on her subject. She began interviewing Van Allen in his office at the University of Iowa in 1998, and on until his death in 2006 at the age of 91 .

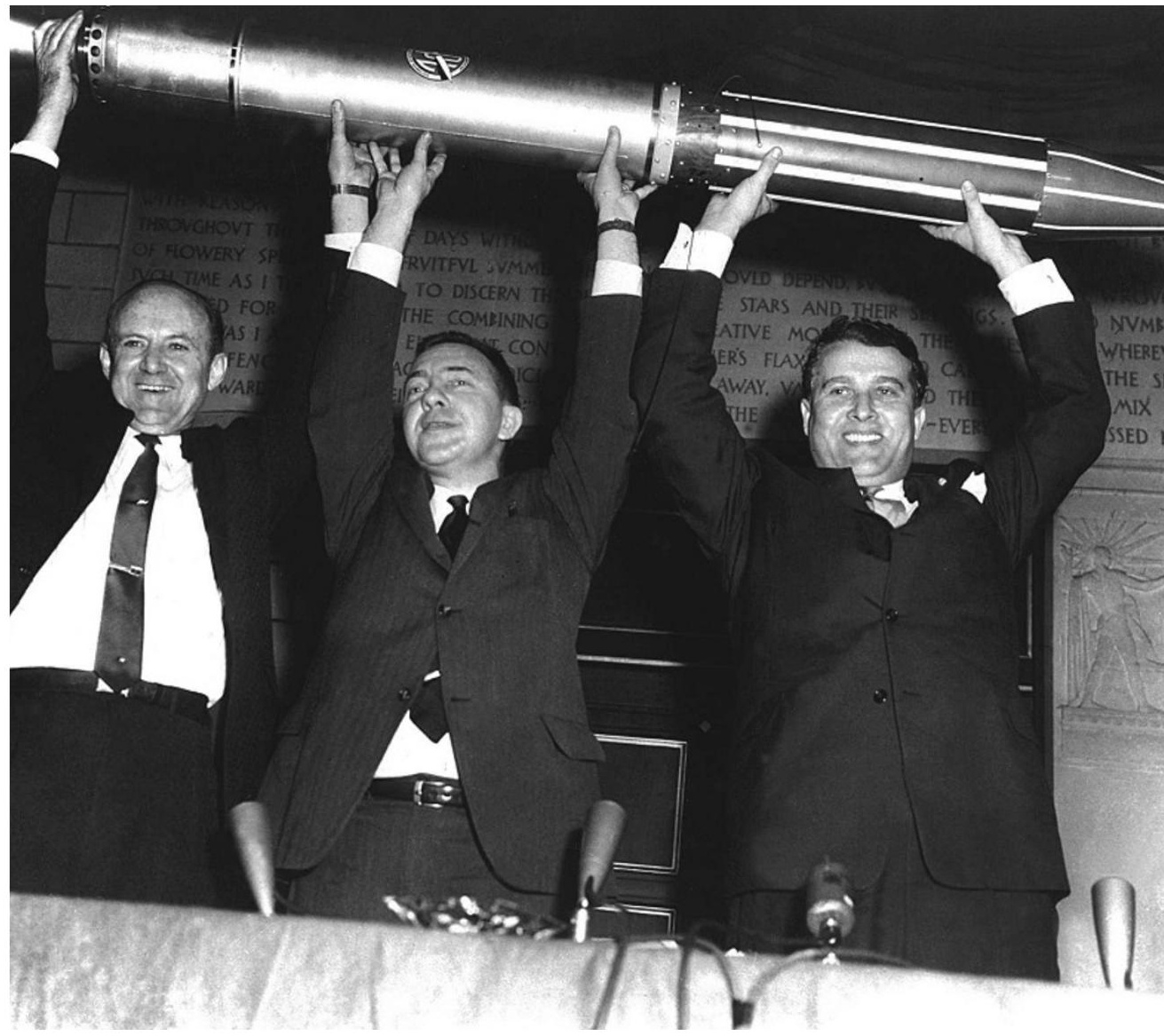

A model of Explorer 1 held by (from left) William Pickering, James Van Allen and Wernher von Braun.

A sign on his door gave its exact longitude and latitude, reflecting the dry humour of an individual whose scientific competence never overshadowed his human qualities. To her credit, Foerstner portrays a complete human being, not a scientific automaton, with richly detailed references to his wife Abigail, his children, other relatives, adoring students, and other rocket scientists. One photograph shows Van Allen whimsically holding up a T-shirt proclaiming: "ACTUALLY, I AM A ROCKET SCIENTIST."

Like Pickering and von Braun, Van Allen was passionately preoccupied with unlocking secrets in the then-new realm of space. Von Braun's

$\mathrm{V}-2 \mathrm{~s}$, which terrified the residents of wartime London and Antwerp, were a gift to Van Allen, enabling his radiation detectors to pierce "the cosmic ray ceiling of the atmosphere", as he put it.

The drive to get his instruments into space with little or no budget forced Van Allen to be inventive. He initially flew his instruments on weather balloons, then created the smaller, cheaper Aerobee research rocket to replace the V-2, and eventually launched small rockets from navy balloons to reach even z higher; he christened these 'rockoons'

Van Allen's achievements as a space pioneer far surpass the discovery of the radiation belt named after him. Nevertheless, the Explorer 1 mission that helped lay the foundation for space science proved to be a hard act to follow and obscured many of his later accomplishments that reached well beyond Earth.

After being carried on a series of Earthorbiting science satellites called Injun, his clever instruments next flew to Venus on Mariner 2, and then across the Solar System aboard Pioneer 10. His guiding presence accompanied Voyager 2 when it flew its 12-year grand tour of the four outer giant planets that ended at Neptune in 1989.

As Foerstner concludes: "His instruments on board more than 200 rockets, satellites and space probes transmitted data over six decades. Pioneer 10 alone, launched for a 21-month mission in 1972, sent Van Allen more than 30 years of readings that helped us recognize that the boundary of the Solar System extended billions of miles past Pluto." A journey indeed. William E. Burrows is director and founder of the Science, Health and Environmental Reporting Program, New York University, 20 Cooper Square, New York, New York 10003, USA. 